University of Massachusetts Amherst

ScholarWorks@UMass Amherst

2006

\title{
A small acidic protein 1 (SMAP1) mediates responses of the Arabidopsis root to the synthetic auxin 2,4-dichlorophenoxyacetic acid
}

\author{
A Rahman \\ A Nakasone \\ T Chhun \\ C Ooura \\ KK Biswas
}

See next page for additional authors

Follow this and additional works at: https://scholarworks.umass.edu/biology_faculty_pubs

Part of the Biology Commons

\section{Recommended Citation}

Rahman, A; Nakasone, A; Chhun, T; Ooura, C; Biswas, KK; Uchimiya, H; Tsurumi, S; Baskin, TI; Tanaka, A; and Oono, $\mathrm{Y}$, "A small acidic protein 1 (SMAP1) mediates responses of the Arabidopsis root to the synthetic auxin 2,4-dichlorophenoxyacetic acid" (2006). Plant Journal. 16.

https://doi.org/10.1111/j.1365-313X.2006.02832.x

This Article is brought to you for free and open access by the Biology at ScholarWorks@UMass Amherst. It has been accepted for inclusion in Biology Department Faculty Publication Series by an authorized administrator of ScholarWorks@UMass Amherst. For more information, please contact scholarworks@library.umass.edu. 


\section{Authors}

A Rahman, A Nakasone, T Chhun, C Ooura, KK Biswas, H Uchimiya, S Tsurumi, TI Baskin, A Tanaka, and Y Oono 


\title{
A small acidic protein 1 (SMAP1) mediates responses of the Arabidopsis root to the synthetic auxin 2,4-dichlorophenoxyacetic acid
}

\author{
Abidur Rahman ${ }^{1,2}$, Akari Nakasone ${ }^{1,5, \dagger}$, Tory Chhun ${ }^{4}$, Chiharu Ooura ${ }^{3, \ddagger}$, Kamal Kanti Biswas ${ }^{1,5}$, Hirofumi Uchimiya ${ }^{3,5}$, Seiji \\ Tsurumi $^{4}$, Tobias I. Baskin ${ }^{2}$, Atsushi Tanaka ${ }^{1, \dagger}$ and Yutaka Oono ${ }^{1,3, t, *}$ \\ ${ }^{1}$ Research Group for Plant Resource Application, Japan Atomic Energy Research Institute, Takasaki 370-1292, Japan, \\ ${ }^{2}$ Biology Department, University of Massachusetts, Amherst, MA 01003, USA, \\ ${ }^{3}$ Advanced Science Research Center, Japan Atomic Energy Research Institute, Takasaki 370-1292, Japan, \\ ${ }^{4}$ Center for Supports to Research and Education Activities Isotope Division, Kobe University, Kobe 657-8501, Japan, and \\ ${ }^{5}$ Institute of Molecular and Cellular Biosciences, The University of Tokyo, Tokyo 113-0032, Japan
}

Received 3 March 2006; revised 11 May 2006; accepted 30 May 2006

*For correspondence (fax +81 27346 9688; e-mail ohno.yutaka@jaea.go.jp).

†Present address: Radiation-Applied Biology Division, Japan Atomic Energy Agency, Takasaki, 370-1292, Japan.

${ }^{\ddagger}$ Present address: Methodology Research Group, Research Development Division, Fujirebio Inc., Hachioji, Tokyo 192-0031, Japan.

${ }^{\S}$ Present address: Department of Environmental Life Sciences, Tohoku University, Sendai 980-8577, Japan.

\begin{abstract}
Summary
2,4-dichlorophenoxyacetic acid (2,4-D), a chemical analogue of indole-3-acetic acid (IAA), is widely used as a growth regulator and exogenous source of auxin. Because 2,4-D evokes physiological and molecular responses similar to those evoked by IAA, it is believed that they share a common response pathway. Here, we show that a mutant, antiauxin resistant1 (aar1), identified in a screen for resistance to the anti-auxin p-chlorophenoxyisobutyric acid (PCIB), is resistant to 2,4-D, yet nevertheless responds like the wild-type to IAA and 1-napthaleneacetic acid in root elongation and lateral root induction assays. That the aar1 mutation alters 2,4-D responsiveness specifically was confirmed by analysis of GUS expression in the DR5:GUS and HS:AXR3NT-GUS backgrounds, as well as by real-time PCR quantification of IAA11 expression. The two characterized aar1 alleles both harbor multi-gene deletions; however, 2,4-D responsiveness was restored by transformation with one of the genes missing in both alleles, and the 2,4-D-resistant phenotype was reproduced by decreasing the expression of the same gene in the wild-type using an RNAi construct. The gene encodes a small, acidic protein (SMAP1) with unknown function and present in plants, animals and invertebrates but not in fungi or prokaryotes. Taken together, these results suggest that SMAP1 is a regulatory component that mediates responses to 2,4-D, and that responses to 2,4-D and IAA are partially distinct.
\end{abstract}

Keywords: anti-auxin, Arabidopsis thaliana, indole-3-acetic acid (IAA), p-chlorophenoxy-isobutyric acid (PCIB), signal transduction.

Introduction

The plant hormone, auxin, influences plant behavior from embryogenesis to senescence. Over the past decade, the mechanism of action of auxin has been revealed by a combination of biochemical and genetic methodologies (Dharmasiri and Estelle, 2004; Dharmasiri et al., 2005; Kepinski and Leyser, 2005; Woodward and Bartel, 2005). The mechanism of auxin signal transduction has been discovered to rely on ubiquitin-mediated proteolysis, and many of the participating proteins and interactions have been identified. In outline, auxin directly binds to a TIR1 protein, a component of a multisubunit E3 ubiquitin ligase, named $\mathrm{SCF}^{\mathrm{TIR} 1}$; auxin binding promotes the interaction of $\mathrm{SCF}^{\mathrm{TIR} 1}$ with members of a large family of regulatory proteins, collectively termed AUX/IAA proteins. SCF ${ }^{\text {TIR1 }}$ ubiquitinylates the AUX/IAA protein, eliciting its degradation. The destruction of the AUX/IAA protein allows the release of one or more auxin response factors (ARFs), transcription factors that regulate auxin-dependent gene expression and hence downstream events. 
Although these studies have illuminated auxin signal transduction, many areas remain dark. For example, certain responses to auxin have been reported to be mediated by hetero-trimeric G-proteins (Ullah et al., 2001, 2003) but it is not known how these relate to the $\mathrm{SCF}^{\mathrm{TIR} 1}$ complex pathway. Additionally, plants respond to exogenous auxin concentrations over many orders of magnitude, and it is not clear how the $\mathrm{SCF}^{\mathrm{TIR} 1}$ complex pathway accommodates such a large range of concentrations. Finally, the process of polar auxin transport appears to be linked to auxin action more deeply than simply by the regulation of ambient concentration, but the details of this connection remain obscure.

To date, the genetic approaches for the most part have screened for mutants with altered responses to auxin; however, considering the absolute necessity of auxin for embryogenesis, screening seedlings against auxin may be limited. An alternative approach is to screen for seedlings that have an aberrant response to compounds that modify or antagonize auxin responsiveness. To this end, we screened seedlings on $p$-chlorophenoxyisobutyric acid (PCIB), a chemical thought to inhibit early auxin signaling events. Although PCIB is structurally similar to some synthetic auxins (Jönsson, 1961), many years ago it was shown to inhibit several auxin-induced physiological responses competitively (Åberg, 1950, 1951; Burström, 1950). Consistent with these results, Oono et al. (2003) recently showed that $P C I B$ impairs auxin-induced gene expression by inhibiting the auxin-mediated degradation of AUX/IAA proteins through the ubiquitin pathway.

Based on this screen, we recovered a mutant that we named antiauxin resistant1 (aar1). As we report here, in addition to PCIB resistance, aar1 is resistant to the synthetic auxin 2,4-dichlorophenoxyacetic acid (2,4-D), yet responds like the wild-type to the native auxin indole-3-acetic acid (IAA). For decades, 2,4-D has been used as an exogenous source of auxin in experiments and mutant screens, mainly because of its great stability. It is generally accepted that 2,4$D$ and IAA share a common signaling pathway (e.g. Taiz and Zeiger, 2002). The differences recognized between 2,4-D and IAA are in transport, where 2,4-D is suggested to efflux more slowly than IAA, and in metabolism, where 2,4-D is assumed to accumulate inside the cell to a greater extent because of a slower rate of breakdown (Campanoni and Nick, 2005; Delbarre et al., 1996; Jackson et al., 2002; Staswick et al., 2005; Sterling and Hall, 1997).

Nevertheless, the aar1 mutant described here shows specific resistance at both physiological and molecular levels to only one form of auxin, 2,4-D. Measurements of 2,4-D levels in the uptake and metabolism experiments make an explanation based on altered transport or metabolism unlikely. Molecular characterization of this mutant indicates that 2,4-D responsiveness is conferred by SMAP1, a gene with homologues in many eukaryotes, encoding a small, acidic polypeptide of unknown function. The results demonstrate genetically that the response pathways for 2,4-D and IAA are at least partly distinct.

\section{Results}

\section{Identification of the aar1-1 mutant}

The ability of PCIB to interact with the auxin signaling pathway (Oono et al., 2003) prompted us to screen for mutants that are resistant to $\mathrm{PCIB} . \mathrm{M}_{2}$ seeds were germinated on medium containing $20 \mu \mathrm{M}$ PCIB and grown under continuous light for 2 weeks. Seedlings with longer roots were rescued as putative mutants and re-screened after several generations of selfing. Here, we focus on characterization of one line designated antiauxin resistant1 (aar1-1). Backcrossing this mutant to Columbia (wild-type) gave $F_{1}$ progeny all of which showed wild-type PCIB sensitivity, and $F_{2}$ progeny with $\mathrm{PCIB}$ sensitive and resistant plants at a ratio indistinguishable from 3:1 (data not shown), suggesting that aar1-1 is caused by a single, recessive mutation. A homozygous line was established from the back-crossed population and used for further characterization. Subsequently, we found a second allele, aar1-2, which is described below in the mapping section.

The morphological characters of the aar1-1 seedlings were similar to wild-type except the mutant had longer hypocotyls than wild-type in both light and darkness, although the difference was greater in the light (Figure 1, Table 1). In mature plants, aar1-1 appeared indistinguishable from wild-type, confirmed by measuring several parameters, including time of bolting, number of inflorescence stems, length of the primary inflorescence, and flowering time (data not shown).

Root elongation, lateral root induction, and germination in aar1-1 are resistant specifically to 2,4-D

To characterize the response of aar1-1 to auxins and other compounds, we germinated seeds on growth medium supplemented with the compound of interest, and measured root length (Figure S1). The aar1-1 mutant responded to IAA, 1-naphthalene acetic acid (NAA) and indolebutyric acid (IBA), as did the wild-type, but was less sensitive to 2,4-D. Furthermore, aar1-1 responded to the auxin transport inhibitors triiodobenzoic acid (TIBA) and naphthylpthalamic acid (NPA), as did the wild-type, suggesting that auxin transport is not perturbed in aar1-1. Finally, aar1-1 roots showed a wild-type response to ethylene, cytokinin and methyl jasmonate, demonstrating that the aar1-1 growth phenotype is not widely pleiotropic.

Because the differential response of aar1-1 roots to auxins is unusual among extant mutants, we performed a doseresponse assay for root elongation and lateral root production. The mutant showed a strong resistance to 2,4-D in 
(a)

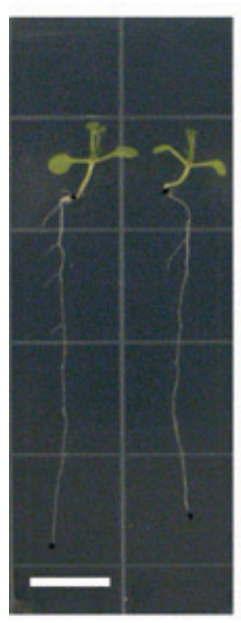

(c)

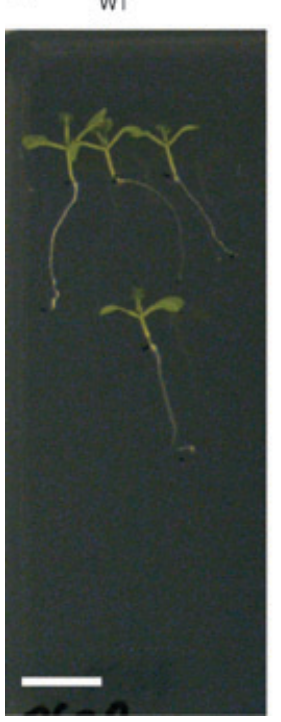

aar1-1

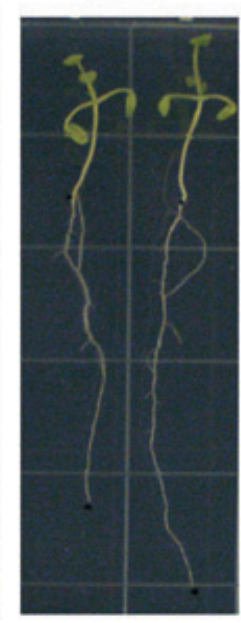

aar1-1

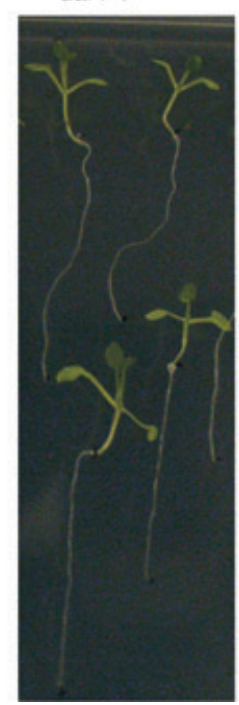

(b)

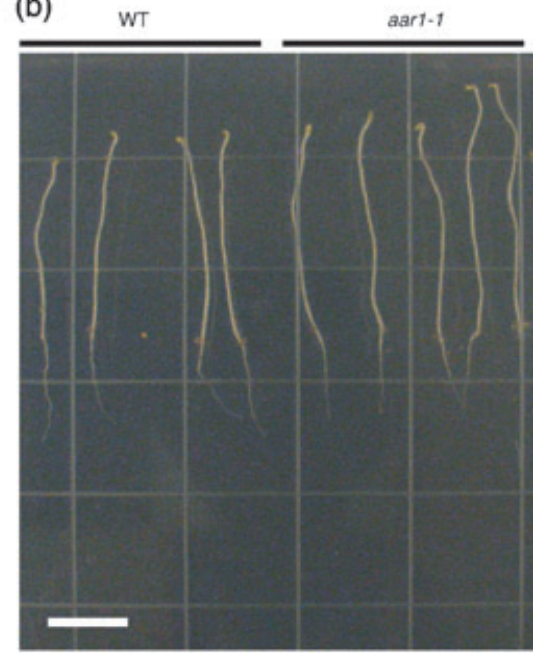

(d)

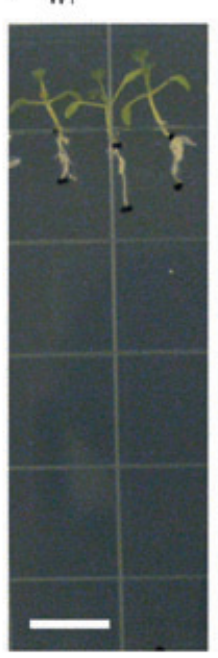

Figure 1. Photographs illustrating seedling phenotypes of wild-type (WT) and aar1-1.

(a) 11-day-old light-grown seedlings.

(b) 7-day-old dark-grown seedlings.

(c) 10-day-old light-grown seedlings exposed to $20 \mu \mathrm{M}$ PCIB or (d) $40 \mathrm{~nm}$ 2,4-D. Bars $=1 \mathrm{~cm}$.
Table 1 Comparison of growth parameters in wild-type and aar1-1

\begin{tabular}{llll}
\hline & \multicolumn{2}{l}{ Light-grown seedlings } & \\
\cline { 2 - 3 } Genotype & $\begin{array}{l}\text { Hypocotyl } \\
\text { length }(\mathrm{cm})\end{array}$ & $\begin{array}{l}\text { Root } \\
\text { length }(\mathrm{cm})\end{array}$ & $\begin{array}{l}\text { Dark-grown seedlings } \\
\text { Hypocotyl length }(\mathrm{cm})\end{array}$ \\
\hline Wild-type & $0.31 \pm 0.05$ & $4.66 \pm 0.74$ & $2.23 \pm 0.28$ \\
aar1-1 & $0.69 \pm 0.11$ & $4.62 \pm 0.68$ & $2.44 \pm 0.37$ \\
\hline
\end{tabular}

Ten-day-old light-grown and 7-day-old dark-grown seedlings were used. Data are means \pm SD.

${ }^{*} 0.01<P<0.05$.

elongation and lateral root formation, but had a wild-type response to IAA and NAA (Figure 2). Root elongation in aar1-1 was resistant to $\mathrm{PCIB}$, whereas lateral root formation responded similarly to wild-type. The experiments in Figure 2 were performed by plating seeds on supplemented media, and so an observed difference between the genotypes might reflect differences in either germination or elongation or both. However, transplanting seedlings onto media containing one of the above four compounds (2,4-D, $I A A, N A A$ and $P C I B)$ and measuring the response five days later gave results that were strictly comparable to the continuous treatment (data not shown). Taken together, the dose-response data show that, for root growth and lateral root formation, aar1-1 responds like wild-type to IAA and NAA but is resistant to 2,4-D.

To explore other responses, we investigated the recently reported synergism between auxin and abscisic acid in seed germination (Brady et al., 2003). In the absence of auxin, germination of aar1-1 seeds was more sensitive to abscisic 
Figure 2. Root elongation (left panels) and lateral root production (right panels) versus concentration of PCIB, IAA, NAA and 2,4-D.

Symbols show mean \pm SE. Data are from two to five independent experiments, with 10-12 seedlings per treatment.
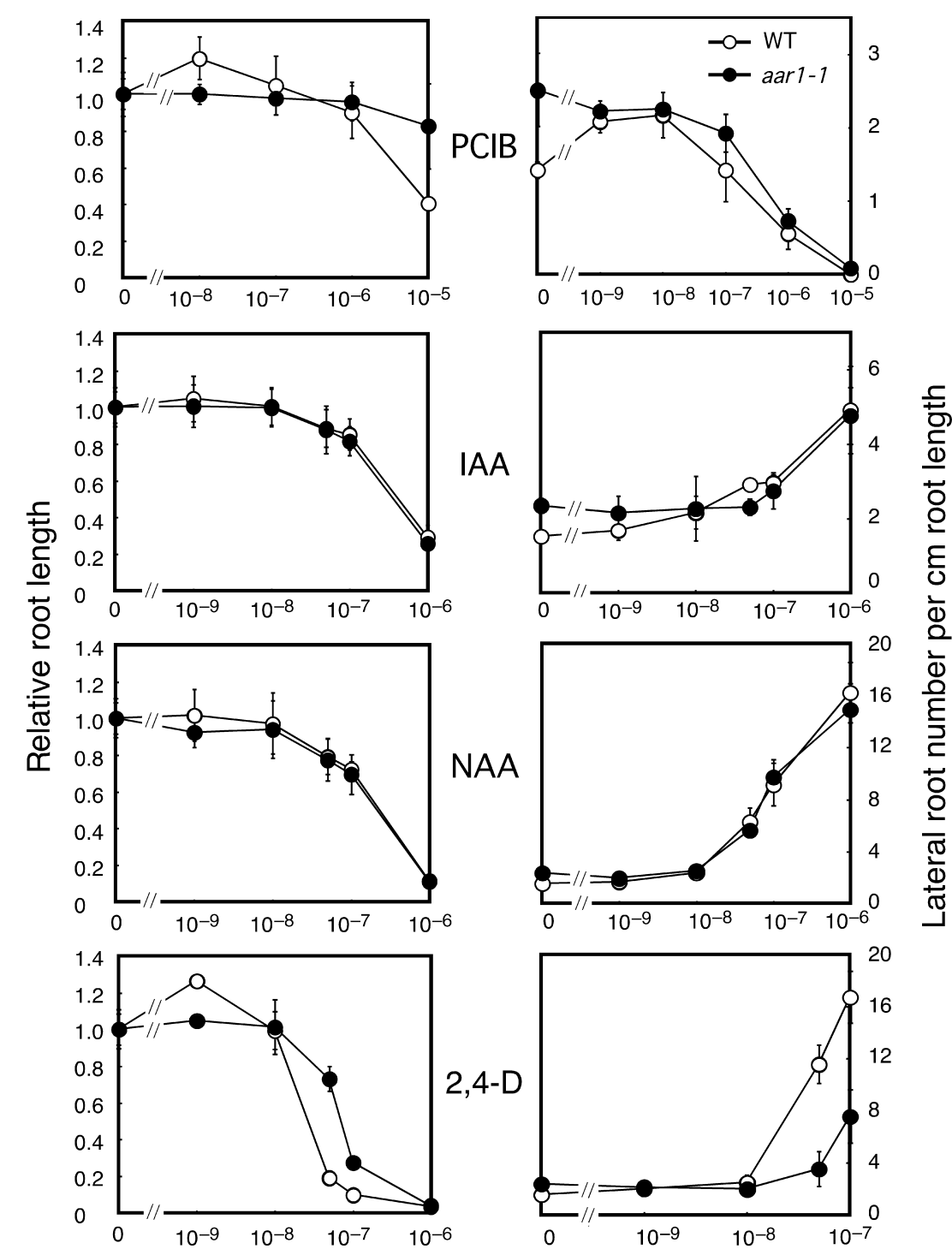

Concentration (M) acid compared to that of wild-type (Figure S2). As expected, treatment of seeds with either IAA, 2,4-D or IBA enhanced the sensitivity of wild-type seeds to abscisic acid; however, in aar1-1, while IAA enhanced sensitivity to abscisic acid as effectively as in the wild-type, 2,4-D was ineffective, supporting the notion that this mutant is specifically resistant to the synthetic auxin.

\section{Auxin-dependent gene expression and proteolysis in aar1-1}

Our physiological data indicate that aar1-1 is specifically resistant to 2,4-D. To understand the molecular consequences of this mutation, we studied auxin-induced gene expression first by examining DR5:GUS staining (UImasov et al., 1997). We crossed a line harboring the DR5:GUS construct into the aar1-1 background and examined the GUS expression pattern in plants homozygous for both aar1-1 and DR5:GUS (Figure 3). IAA stimulated DR5:GUS expression similarly in both genotypes, whereas $2,4-D$ at all concentrations was less effective in aar1-1 compared to the wild-type. Likewise, we observed a specific loss of 2,4-D responsiveness in aar1-1 for the expression of a different auxin-sensitive reporter (BA:GUS; Oono et al., 1998) (data not shown). For each reporter, the response pattern was confirmed in lines from three independent crosses.

To analyze directly the effects of IAA and 2,4-D on gene expression, we used real-time RT-PCR to quantify the steady-state level of the transcript of an endogenous auxin-responsive gene, IAA11, a member of AUX/IAA family (Abel et al., 1995). In terms of stimulating IAA11 expression, 


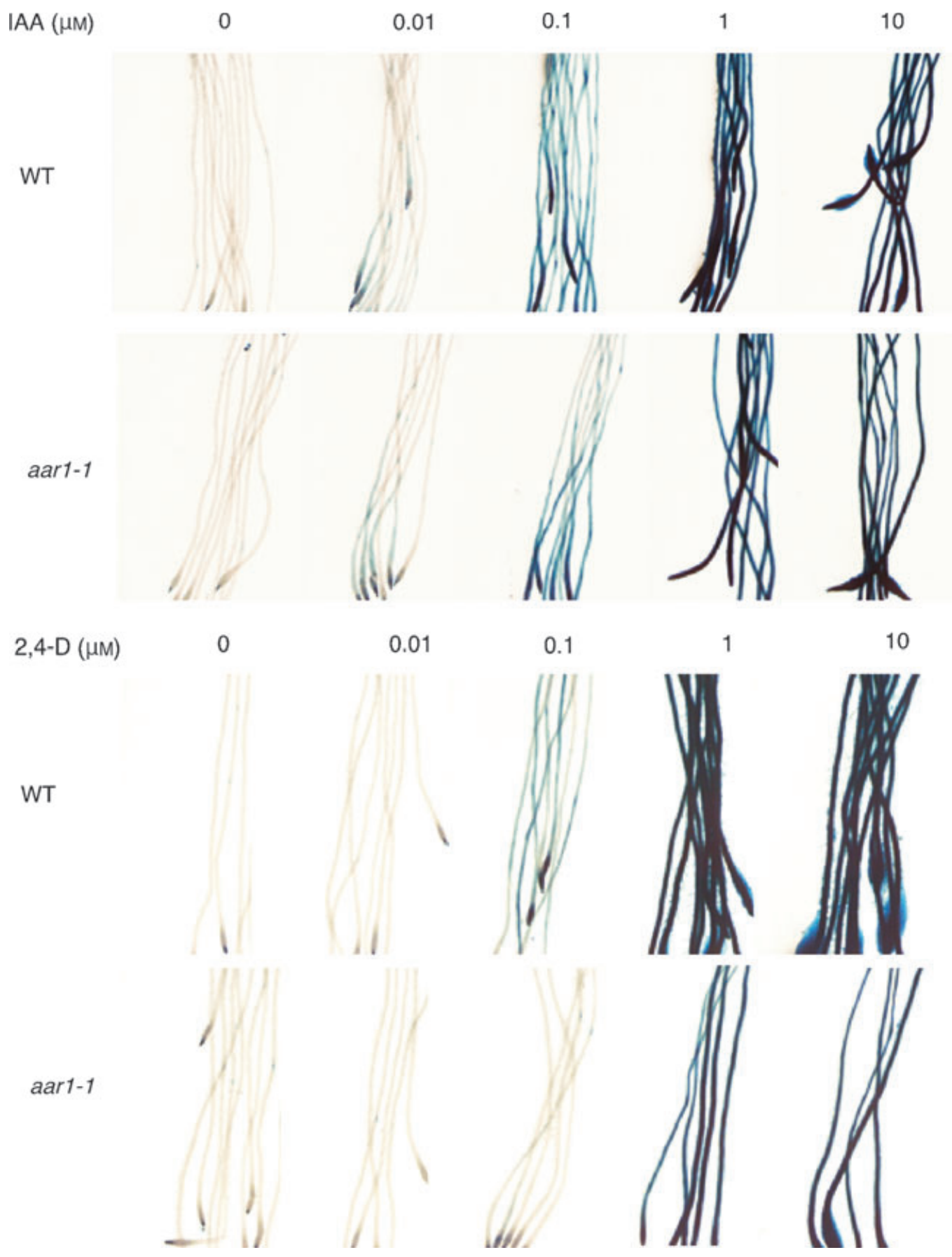

Figure 3. DR5:GUS expression in wild-type and aar1-1 in response to IAA and 2,4-D. Seedlings were exposed to the auxins in liquid for $6 \mathrm{~h}$.

the differences between the genotypes on IAA were not significant, whereas 2,4-D was significantly less effective $(P<0.02)$ in aar1-1 compared to wild-type (Figure 4$)$. In aar11 , the lowered effectiveness of 2,4-D in stimulating not only the accumulation of the IAA11 message but also DR5- and $B A$-driven GUS expression suggests that AAR 1 is a component of a response pathway that recognizes 2,4-D specifically.
To gain further insight into the status of auxin signaling in the aar1-1 mutant, we took advantage of the HS:AXR3NTGUS construct, which allows the stability of an AUX/IAA protein (AXR3) to be directly imaged (Gray et al., 2001). We crossed the HS:AXR3NT-GUS construct into the aar1-1 background and assessed protein stability in lines homozygous for both aar1-1 and HS:AXR3NT-GUS (Figure 5). In aar1-1 roots, IAA promoted the degradation of the AUX/IAA 

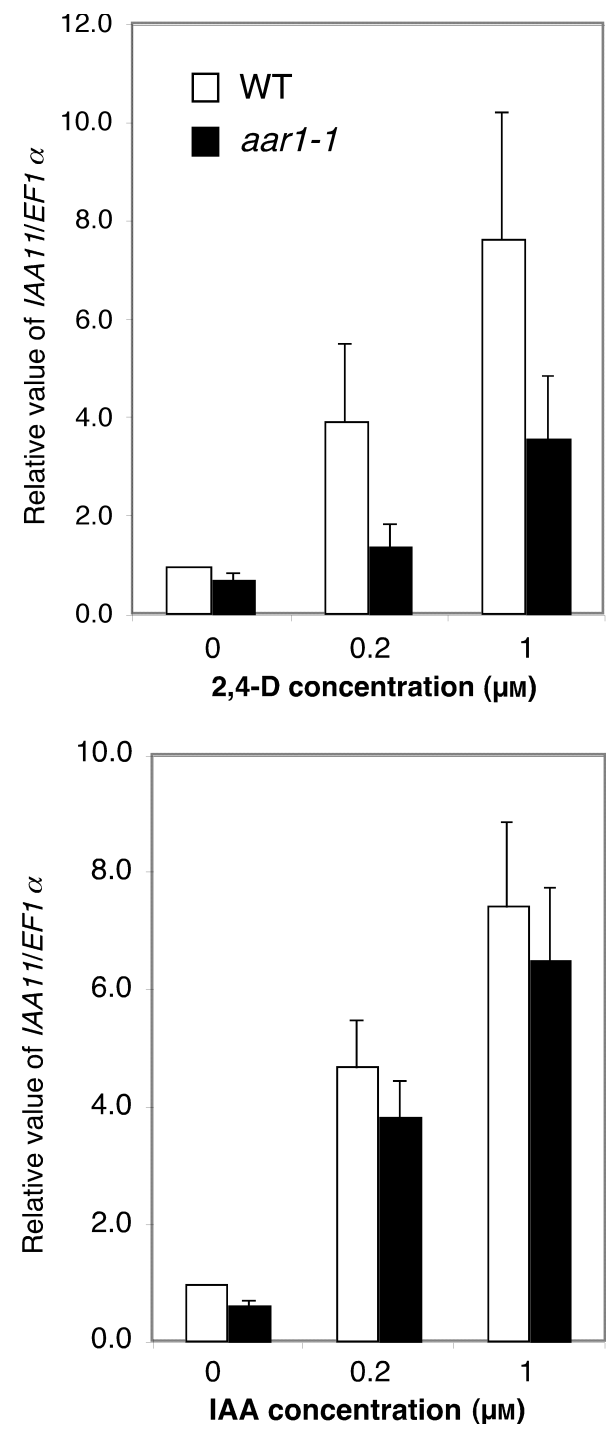

Figure 4. Real-time PCR analysis of the expression of the IAA11 gene in wildtype and aar1-1.

Roots from 7-day-old seedlings were treated in liquid with or without IAA or 2,4-D for $2 \mathrm{~h}$. The copy number of IAA11 transcripts was calculated by normalizing against the number of copies of the EF1 $\alpha$ transcript. Results are expressed as the mean \pm SD for the ratio of IAA11 to EF1 $\alpha$ copy number (with the untreated, wild-type ratio assigned a value of 1) from five and four independent experiments for 2,4-D and IAA, respectively.

reporter protein as effectively as in the wild-type; however, $0.1 \mu \mathrm{M} 2,4-D$ was less effective in aar1-1 than in the wildtype. At a high concentration, 2,4-D was as effective as IAA in promoting the reporter protein degradation in aar1-1, which is in accordance with our observations on both growth and gene expression showing that aar1-1 is able to respond to 2,4-D at high concentrations. As for PCIB, in the wild-type, low concentrations promoted the degradation of the AUX/ IAA protein whereas high concentrations increased its stability; in contrast, in aar1-1, PCIB at any concentration did not affect protein stability. These results indicate that resistance of aar1-1 towards both PCIB and 2,4-D is due to an alteration upstream of AUX/IAA protein degradation.

\section{Uptake and metabolism of 2,4-D are unaltered in aar1-1}

Conceivably, the specificity of aar1-1 towards 2,4-D resides in the transport or metabolism. To explore these possibilities, we first compared the accumulation of radiolabeled 2,4$D$ into the apical $3 \mathrm{~mm}$ of the root tip over a $1 \mathrm{~h}$ period. The accumulation of 2,4-D was indistinguishable in wild-type and aar1-1 (Table 2), inconsistent with the idea that the selective resistance of this mutant towards 2,4-D is associated with transport. We next assessed metabolism by chromatographic analysis of root extracts following 8 or $24 \mathrm{~h}$ incubation in labeled 2,4-D (Figure 6). There was no change in the amount of radioactivity in any of the three resolved fractions, with the great majority remaining unmetabolized (fraction $\mathrm{C}$ ), suggesting that the metabolism of 2,4-D is not altered in aar1-1.

\section{At4g13520 mediates $P C I B$ and 2,4-D responsiveness}

Mapping revealed that $A A R 1$ is located on chromosome 4 between T9E8-2-2 and F18A5-0-1 (Figure S3 and Table S1). Thermal assymetric interlaced (TAIL)-PCR and sequencing analyses delineated a deleted region between 9692 and 53586 nt on T6G15 (Figure 7a and Figure S3). This interval contains eight annotated genes, none of which to our knowledge has been implicated in auxin responses.

To identify the gene(s) responsible for the aar1-1 phenotype, we examined available insertional mutants for these loci and found one, ET-202, from an enhancer trap population, that is resistant to PCIB (Table S2), has a long hypocotyl and 2,4-D-resistant root growth (data not shown). The PCIBresistant phenotype in this line was recessive to wild-type, and all $F_{1}$ progeny derived from a cross with aar1-1 were PCIB-resistant, indicating that the mutation is allelic to aar11. Therefore, we designate ET-202 as aar1-2. TAIL-PCR and sequencing showed that four of the eight genes deleted in aar1-1 could be disrupted by the transposon in aar1-2 (Figure 7a).

To determine the involvement of these disrupted genes in the phenotype of aar1, we used complementation. As shown in Figures 7(b) and 8, aar1-1 lines transformed with fragments containing only At4g13520 (e.g. the 'B/S' fragment) recovered both $\mathrm{PCIB}$ and 2,4-D sensitivity in root growth, whereas fragments containing neighboring genes (e.g. the ' $X / B^{\prime}$ ' fragment) failed to restore sensitivity. Some of the lines transformed with At4g13520 had shorter hypocotyls, although not as short as the wild-type.

Although these complementation tests demonstrate that At4g 13520 restores sensitivity to 2,4-D and PCIB, several genes are deleted in both aar1 alleles. To characterize the 


\section{concentration $(\mu \mathrm{M})$}

0

0.1

50
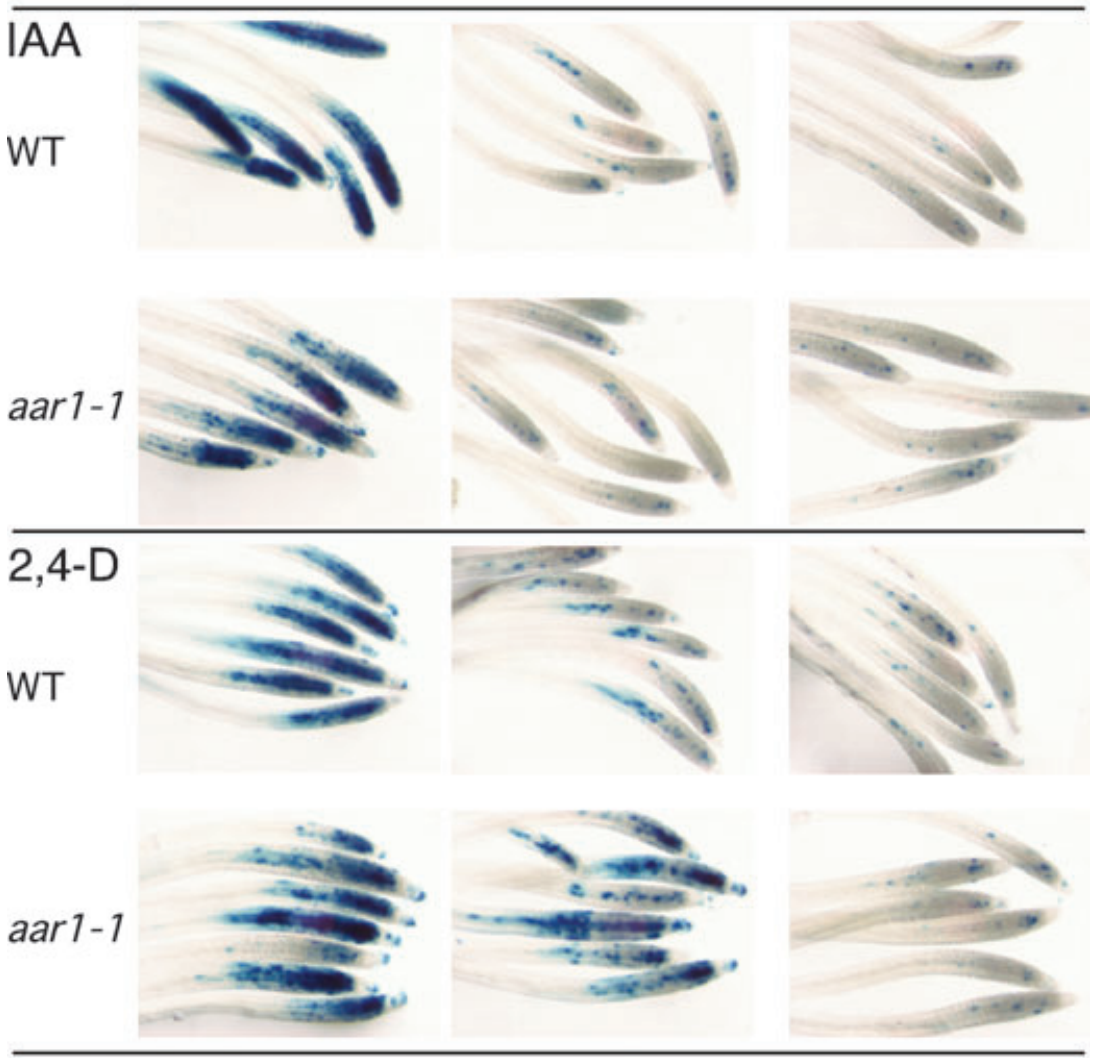

$\mathrm{PCIB}$

WT
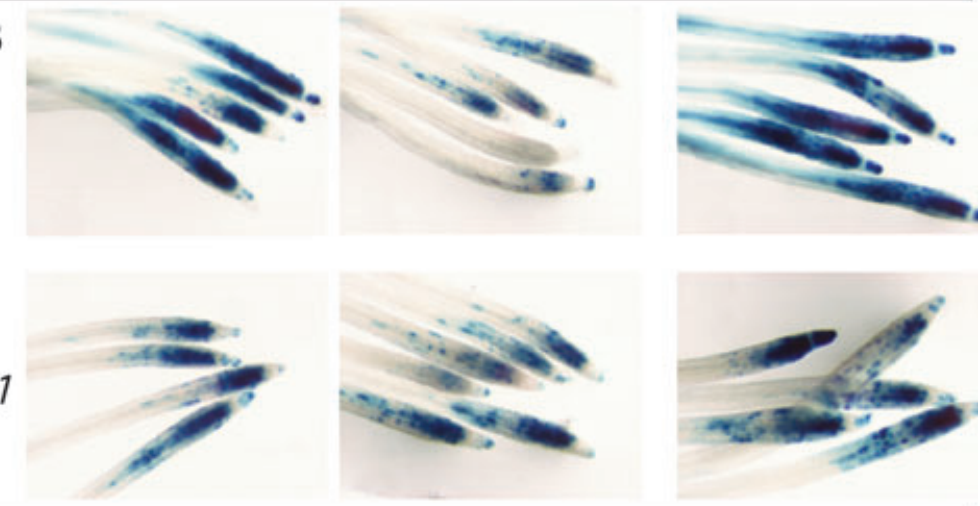

Figure 5. Stability of an AUX/IAA protein in wild-type and aar1-1.

Wild-type and aar1-1 lines expressing HS:AXR3NT-GUS were incubated in liquid growth medium without supplements at $37^{\circ} \mathrm{C}$ for $120 \mathrm{~min}$, transferred to fresh medium at $23^{\circ} \mathrm{C}$ for $30 \mathrm{~min}$, incubated for $120 \mathrm{~min}$ in growth medium supplemented as indicated, and then stained with X-gluc for $2 \mathrm{~h}$. That the heat-shock promoter is not sensitive to the growth regulators was ascertained by replicate experiments with lines expressing HS:GUS (data not shown). Seedlings were cleared for photography.
Table 2 Accumulation of $\left[{ }^{14} \mathrm{C}\right]$ 2,4-D in wild-type and aar1-1

\begin{tabular}{ll}
\hline Line & $\begin{array}{l}\text { Radioactivity } \\
\text { (dpm) }\end{array}$ \\
\hline $\begin{array}{ll}\text { Wild-type } \\
\text { aar1-1 }\end{array}$ & $181 \pm 40.9$ \\
\hline
\end{tabular}

Data are the mean of 12 experiments \pm SD.

consequence of the loss of only At4g13520, we used RNA interference. $T_{2}$ lines expressing double-strand RNA constructs against At4g13520 segregated seedlings resistant to
$\mathrm{PCIB}$, whereas those expressing constructs against the neighboring genes (i.e. At4g13490, At4g13500, At4g 13510 and At4g13530) did not increase PCIB resistance (data not shown). In homozygous lines for constructs targeting At4g 13510 and 13520 (510i and 520i lines, respectively), the At4g 13520 mRNA level was decreased in the 520i lines, in some cases to undetectable levels, but was not decreased in the 510i lines (Figure 9a). Most of the 520i lines but none of the $510 \mathrm{i}$ lines generated resistance to PCIB and 2,4-D that was indistinguishable from that of aar1-1 (Figure 9b-d). The 520i lines gave rise to hypocotyls longer than wild-type (Figure 9e), indicating that the At4g 13520 message is able to 

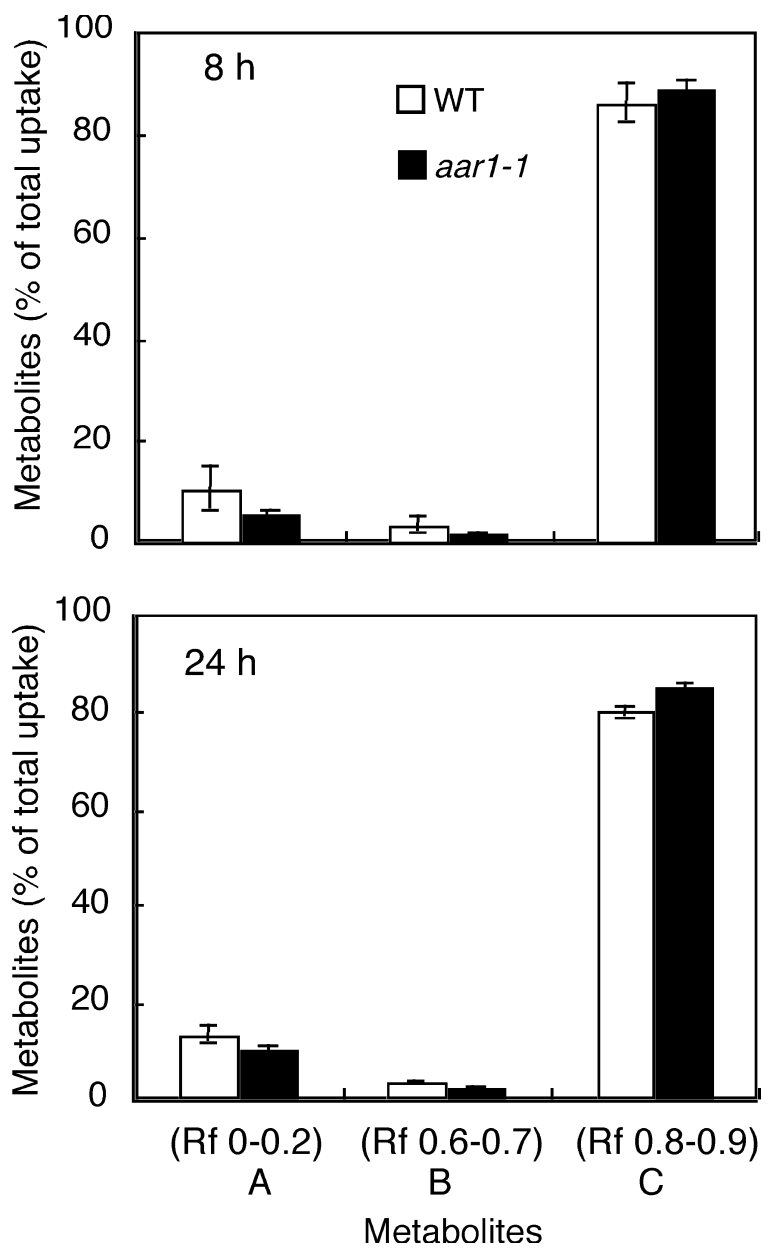

Figure 6. Metabolism of 2,4-D in wild-type and aar1-1.

Seedlings were incubated in radio-labeled 2,4-D for 8 or $24 \mathrm{~h}$ and extracts chromatographed. Fraction $C$ has been reported to contain 2,4-D, whereas fractions $A$ and $B$ contain glucosinate and amino acid conjugates, respectively (Riov et al., 1979). Bars indicate mean \pm SD from four replicate experiments.

shorten hypocotyl length. The RNAi results, taken together with the complementation and the isolation of aar1-2, indicate that At4g 13520 confers sensitivity to PCIB and 2,4-D.

\section{At4g13520 encodes a small, acidic protein of unknown function}

At4g 13520 encodes a small protein (62 amino acids, calculated molecular weight $6.9 \mathrm{kDa}$ ) of considerable acidity (pK 3.3); therefore, we have named it small acidic protein 1 (SMAP1). The Arabidopsis genome contains a related gene, At3g24280, which we designate SMAP2. These two proteins share $62 \%$ identity at the nucleotide level and $43 \%$ at the predicted amino acid level. BLAST searches of ESTs revealed putative homologues of SMAP1 with highly conserved Cterminal domains, rich in phenylalanine and aspartic acid ( $F /$ D), in the genomes of vertebrates, invertebrates, and plants, but not in fungi, bacteria, or archaea (Figure 10). The SMAP1 sequence contains no recognizable signal sequences, suggesting that it functions in the cytosol. To our knowledge, a function for this protein family has yet to be demonstrated in any organism, and based on BLAST as well as protein structure algorithms, SMAP1 contains no recognized domains; consequently, we suggest that participation in hypocotyl elongation and the 2,4-D response defines the function of SMAP1 as the founding member of a new gene family.

\section{Discussion}

The synthetic auxin and herbicide, 2,4-D, is generally assumed to act through the signal transduction machinery discovered for the native auxin, IAA. Here, we isolate a mutant, aar1, that specifically resists 2,4-D but not IAA in terms of root growth inhibition, lateral root promotion, seed germination in the presence of abscisic acid, and the degradation of AUX/IAA proteins. Further, we show that responsiveness to the synthetic auxin is conferred by a novel gene, SMAP1, a gene that also explains at least partially the long-hypocotyl phenotype of aar1. These results open a door for a better understanding of the action of 2,4-D.

In principle, altered transport could explain the resistance of aar1 towards 2,4-D. Transport is widely accepted as being different between IAA and 2,4-D, with the latter moving at about $10 \%$ of the velocity of the former in polar transport assays (Delbarre et al., 1996; Rubery, 1995). Previously, distinct physiological responses to IAA and 2,4-D, when observed, have often been attributed to differential transport or metabolism (e.g. Campanoni and Nick, 2005; Kawano et al., 2003; Steiger et al., 2002). In fact, a transport regulator handling 2,4-D (and IBA) but not IAA is defective in Arabidopsis rib1 (Poupart and Waddell, 2000; Poupart et al., 2005) and in rice arm2 (Chhun et al., 2005) mutants that have root growth resistant to IBA and 2,4-D but not to IAA.

We ruled out the possibility of aar1 being an auxin transport mutant for several reasons. First, PCIB does not affect auxin transport (Imhoff et al., 2000; Okada et al., 1991). Several mutants in auxin signal transduction show resistance to PCIB whereas mutants in auxin transport do not (Oono et al., 2003). Most of the auxin-transport mutants such as aux1, eir1, tir3 and rib1 show cross-resistance among transport inhibitors, while others such as pin 1 can be phenocopied by treatment of transport inhibitors in wildtype (Fujita and Syono, 1996; Morris, 2000; Poupart and Waddell, 2000), whereas aar1-1 has wild-type sensitivity to two auxin efflux inhibitors, NPA and TIBA, and shows almost no morphological phenotype. Finally, aar1 accumulates 2,4-D to the same extent as the wild-type, in contrast to transport mutants, which typically concentrate auxin at the root tip or have a reduced capability for taking up the exogenous auxin (Ottenschläger et al., 2003; Rahman et al., 
(a)

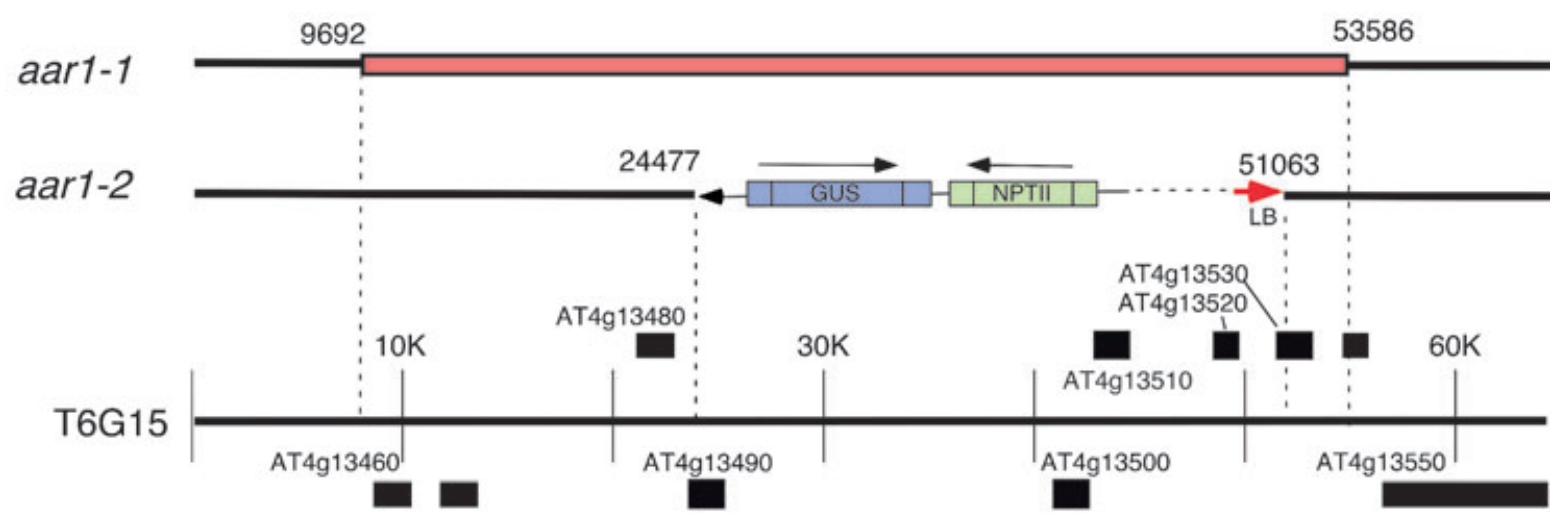

(b)

T6G15(1-60K)

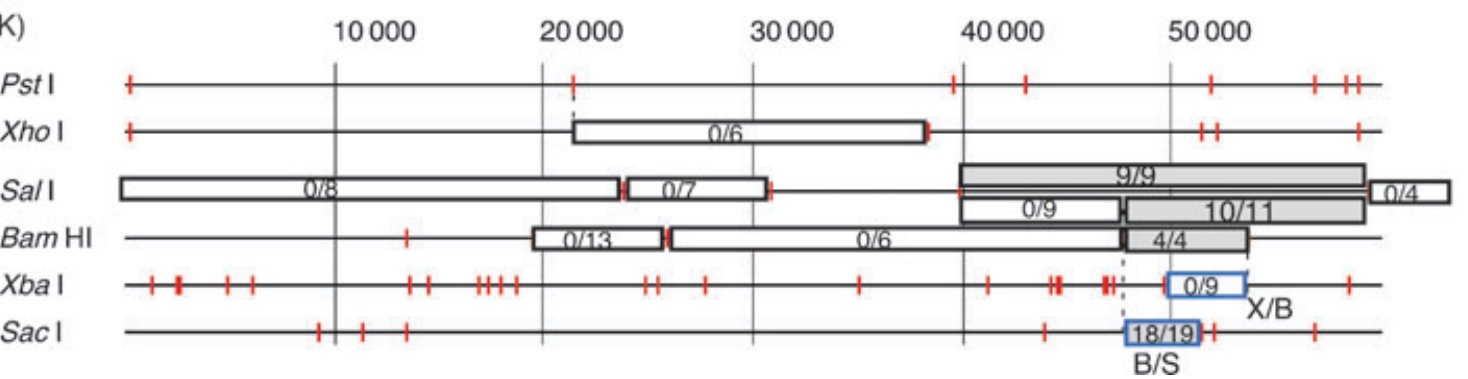

Figure 7. Maps of the aar1 locus and of constructs used for complementation.

(a) The region deleted in aar1-1 is indicated by the red box (top line). The structure of the enhancer-trap insertion in aar1-2 is shown (second line). Annotated open reading frames (both exons and introns) are shown as black boxes (third line).

(b) Restriction enzyme sites (red bars) in this part of the genome. DNA fragments introduced into aar1-1 are shown with gray (complemented) and open (not complemented) boxes, with the number of $T_{1}$ lines for which PCIB-sensitive $T_{2}$ seedlings segregate over the number of independent $T_{1}$ lines assayed indicated within the boxes. Two boxes with blue borders show the fragments, a $3.7 \mathrm{kbp} \mathrm{BamHI/Sacl}(\mathrm{B} / \mathrm{S}$ ) fragment and a $4.0 \mathrm{kbp} \mathrm{Xbal/} \mathrm{BamHI} \mathrm{(X/B)} \mathrm{fragment,} \mathrm{used} \mathrm{to} \mathrm{create}$ the transgenic lines in Figure 8.

Note that (a) and (b) are aligned and drawn to the same scale.

2001). Collectively, these results indicate that the auxin transport machinery functions as normal in this mutant, and the specific resistance of aar1 towards 2,4-D and PCIB seems not to be due to an alteration in transport of these compounds.

A further possibility is that aar1 metabolizes 2,4-D more rapidly than does the wild-type. Although 2,4-D is relatively stable compared to IAA and NAA, a fraction of 2,4-D is known to be metabolized by oxidation, hydroxylation and conjugation (Ribnicky et al., 1996; Sterling and Hall, 1997). Consistently, we observed low levels of conjugative metabolites, identified by slower migration in thin-layer chromatography. No significant difference in the 2,4-D-derived chromatograms was observed in either the short $(8 \mathrm{~h})$ or long-term (24 h), suggesting that 2,4-D metabolism is unaltered in aar1, although we cannot completely exclude the possibility that some 2,4-D metabolites were missed.

Current knowledge about the auxin signal transduction machinery allows for a 2,4-D-specific component. Although the TIR1 auxin receptor is capable of binding both 2,4-D and IAA, its affinity for IAA is 10- to 100-fold greater than for 2,4-D (Dharmasiri et al., 2005; Kepinski and Leyser, 2005). Thus, an additional high-affinity receptor or signaling pathway for 2,4$D$ is plausible insofar as both 2,4-D and IAA evoke physiological responses at comparable exogenous concentrations. The aar1 mutant and the SMAP1 gene provide genetic evidence that 2,4-D has a distinct response pathway from IAA.

The existence of distinct 2,4-D response components is also suggested by other findings. The auxin has been used to isolate cytosolic proteins, from mung bean (Vigna radiata) and peach (Prunus persica), that bind IAA with low affinity but bind 2,4-D and PCIB with high affinity (Sugaya and Sakai, 1996; Sugaya et al., 2000), although the molecular weight of these proteins is higher than that of SMAP1. Recently, a detailed analysis of the transcriptome revealed that IAA and NAA induce mainly similar genes, clustered in one group, whereas 2,4-D, in addition to the common genes induced by IAA and NAA, also induces a subset of genes that cluster in a unique group (Pufky et al., 2003). All these results, together with the isolation of aar1, suggest that a separate response pathway for 2,4-D exists.

We propose that the SMAP1 protein works upstream of ubiquitin-dependent AUX/IAA protein degradation. At or soon after perception, 2,4-D and PCIB require the SMAP1 

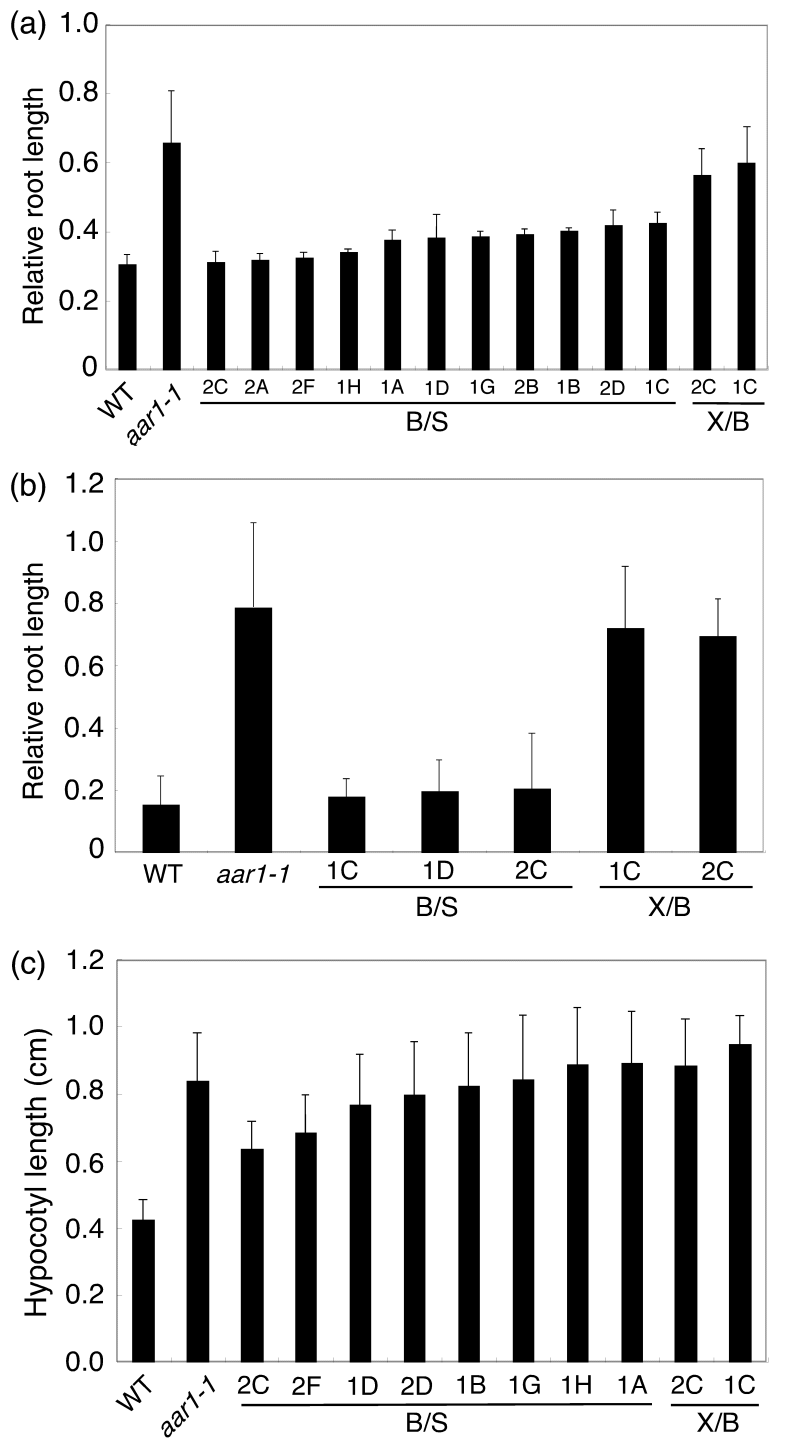

Figure 8. Complementation of the aar1-1 phenotype.

Data compare wild-type, aar1-1, and several independent homozygous transgenic lines generated by transformation of aar1-1 with genomic fragments containing At4g 13520 (B/S) or a neighboring fragment (X/B).

(a, b) Resistance of root elongation to (a) $20 \mu \mathrm{m}$ PCIB or (b) 40 nм 2,4-D. Root length was measured after 10 days and expressed relative to untreated wildtype. Bars show mean \pm SD for at least 6 (a) or 15 (b) seedlings.

(c) Hypocotyl length. Data show the mean length $( \pm S D, n \geq 9$ ) of hypocotyls of untreated, 5-day-old seedlings, grown vertically under the light.

protein to regulate protein degradation as well as downstream events, whereas the SMAP1 protein does not contribute appreciably (or at all) to IAA signaling. Although the function of the SMAP1 protein is unknown, the presence of genes encoding putatively related proteins with highly conserved $F / D$ rich domain in broad range of multi-cellular organisms implies that SMAP1-like proteins are part of a widely conserved biological mechanism, possibly acting in relation to ubiquitin-mediated proteolysis. The mutants deficient in SMAP1 grew without abnormalities (other than the long hypocotyl), possibly because of functional redundancy among the two SMAP proteins or because the endogenous ligand, mimicked by $2,4-D$, has a limited role in plant development. SMAP1 may be an accessory protein that stabilizes the auxin signaling complex, and 2,4-D action in this complex is more sensitive to loss of SMAP1 than is IAA action. Future studies to characterize the biochemical behavior of SMAP1 as well as to identify SMAP1-interacting proteins will help us elucidate the biological role of SMAP1 and untangle the precise mode of action of both 2,4-D and IAA.

\section{Experimental procedures}

\section{Plant materials and growth conditions}

All mutant lines are Arabidopsis thaliana (L.) Heynh, Columbia background, except the ET lines (including aar1-2), which are in the Landsberg erecta background (Sundaresan et al., 1995) and were obtained from Joe Simorowski and Robert Martienssen (Cold Spring Harbor Laboratory, Cold Spring Harbor, NY, USA). The TDNA insertional mutant, amt1;1::T-DNA (Kaiser et al., 2002), was obtained from Brent Kaiser (Australian National University, Canberra, Australia). The transgenic line harboring DR5:GUS (UImasov et al., 1997) was obtained from Jane Murfett and Tom Guilfoyle (University of Missouri, Columbia, MO, USA), and the lines harboring HS:AXR3NT-GUS (Gray et al., 2001) from Stefan Kepinski and Ottoline Leyser (University of York, York, UK). To isolate aar1-1, approximately $30000 M_{2}$ seedlings (representing around $6700 M_{1}$ plants) were screened. $M_{1}$ seed was mutagenized by ion-beam irradiation (Hase et al., 2000). DR5:GUS, BA3:GUS and HS:AXR3NTGUS were introduced into aar1-1 by crossing. Independent lines homozygous for both the transgene and the aar1mutation were identified in the $\mathrm{F}_{3}$ generation by screening for kanamycin and $\mathrm{PCIB}$ resistance.

Surface-sterilized seeds were plated in square plates (D210-16, Simport, Quebec, Canada) on growth medium comprising halfstrength Murashige and Skoog salts ( $\mathrm{pH} 5.8), 1 \% \mathrm{w} / \mathrm{v}$ sucrose and $1 \% \mathrm{w} / \mathrm{v}$ Bacto agar. Two or 4 days after cold treatment at $4^{\circ} \mathrm{C}$ in the dark, plates were transferred to a growth room at $23^{\circ} \mathrm{C}$ under continuous light at an intensity of $20-30 \mu \mathrm{mol} \mathrm{m} \mathrm{m}^{-2} \mathrm{sec}^{-1}$ supplied by fluorescent bulbs (FL 40SSW-37-B, Hitachi, Tokyo, Japan).

For Arabidopsis transformation, Agrobacterium GV3101 (MP90), LBA4404 or EHA105 was used for infection of Arabidopsis by the flower dip protocol (Clough and Bent, 1998). The transgenic plants were identified by growth on medium containing the antibiotic appropriate for the selection marker in the transformation vector. When establishing homozygous lines, single-locus-transformed $T_{1}$ lines were selected by scoring 3:1 (antibiotic resistant:antibiotic sensitive) segregation in the $T_{2}$ population, followed by growing several resistant $T_{2}$ lines and selecting a homozygous $T_{3}$ line based on pure-breeding antibiotic resistance.

\section{Chemicals}

IAA, IBA, 2-4 D, PCIB, TIBA and abscisic acid were purchased from Sigma Chemical Co. (St Louis, MO, USA), NPA from Tokyo Kasei Kogyo (Tokyo, Japan), and other chemicals from Wako Pure Chemical Industries Ltd (Osaka, Japan). Methylene ${ }^{14} \mathrm{C}$ 2,4-D 
(2.035 $\mathrm{MBq} \mu \mathrm{mol}^{-1}$ ) was purchased from American Radiolabeled Chemicals (St Louis, MO, USA).

(a)

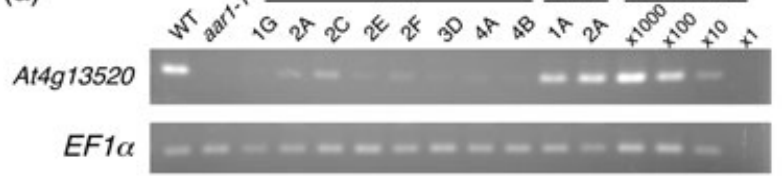

(b)

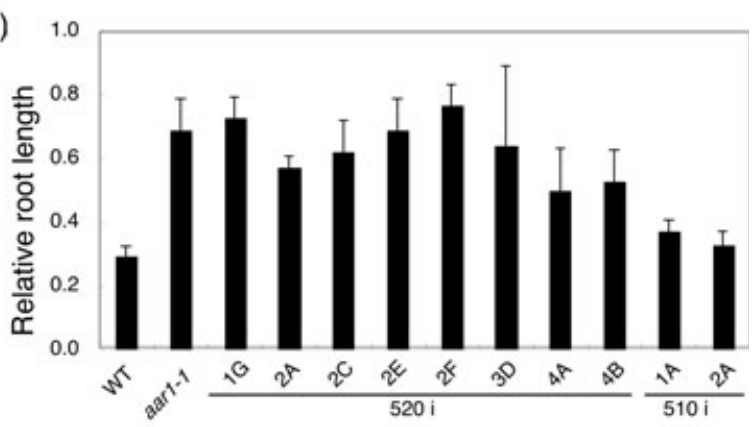

(c)

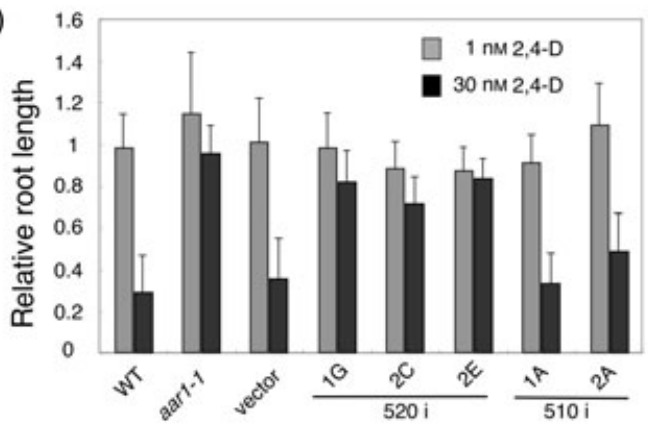

(d)

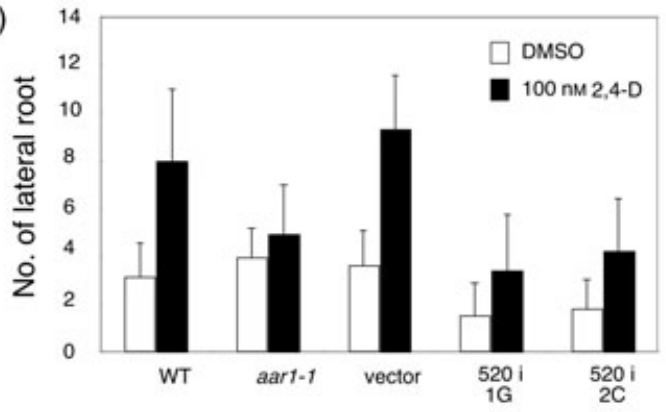

(e)

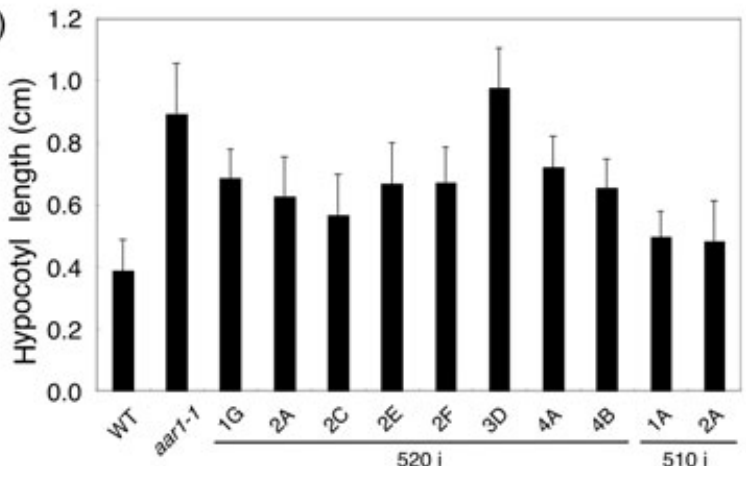

\section{Growth assay}

Surface-sterilized seeds were plated on the surface of the growth medium, supplemented with or without the growth regulators, and grown vertically, as described above. The length of the root and hypocotyl of the seedlings was measured 10 days after germination, unless indicated. For transplantation experiments, seeds were plated on growth medium and were grown for 5 days after germination. On day 5 , seedlings were transferred to medium supplemented with or without the growth regulators and grown vertically for another 5 days. For dark treatment, seeds were irradiated for $8 \mathrm{~h}$ in the growth chamber and transferred to darkness. The number of lateral roots was counted under a dissecting microscope (MZFLIII; Leica, Wetzlar, Germany). The plant growth regulators were dissolved in dimethyl sulfoxide (DMSO) at a concentration 1000x greater than needed. The same concentration of DMSO was added to the control treatments. For germination studies, plants were grown for 4 days after cold treatment, and germination was scored as positive by radicle emergence and cotyledon expansion, as described by Brady et al. (2003).

\section{Gene expression analysis}

GUS histochemical analyses were performed as described by Oono et al. (2003), except that the incubation in GUS staining buffer was for $18 \mathrm{~h}$, unless indicated.

Real-time RT-PCR was performed as described previously (Oono et al., 2003). The specificity of the PCR amplification was checked with a melting curve analysis program and agarose gel electrophoresis of PCR products. The relative amount of specific mRNA was estimated using standard cDNA preparations of known size and molecular concentration, and normalized to the EF1a mRNA level.

\section{2,4-D uptake and metabolism}

The uptake assay was performed as described by Rahman et al. (2001). In brief, 10 apical $3 \mathrm{~mm}$ root tips per treatment were excised

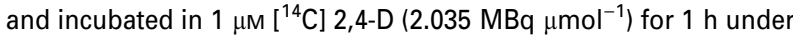
nearly saturating humidity. At the end of incubation, root tips were washed and soaked for overnight in $5 \mathrm{ml}$ liquid scintillation fluid (Scintisol EX-H), and the radioactivity was measured with a scintillation counter (Model LS6500; Beckman Instruments, Fullerton, CA, USA). For the metabolism assay, 5 -day-old seedlings were treated with $1 \mu \mathrm{m}\left[{ }^{14} \mathrm{C}\right] 2,4-\mathrm{D}\left(2.035 \mathrm{MBq} \mu \mathrm{mol}^{-1}\right)$ for 8 or $24 \mathrm{~h}$, and then roots were excised, washed with distilled water twice, and stored at $-80^{\circ} \mathrm{C}$ until used. Roots were treated with $80 \%$ methanol and the extract was subjected to TLC (TLC aluminum sheet silicagel 60 ;

Figure 9. RNAi experiments.

(a) Semi-quantitative RT-PCR for At4g 13520 and EF1 $\alpha$ A4 transcripts. To show that the amplification was not saturated, control DNA was amplified at the same time (for At4g 13520, 1x $=0.001 \mathrm{pg} / \mu \mathrm{l}$ of a $7.38 \mathrm{~Kb}$ Sacl fragment subcloned from T6G15 BAC DNA into pKS; for $E F 1 \alpha, 1 \mathrm{x}=0.1 \mathrm{pg} / \mu \mathrm{l}$ of an amplified cDNA fragment).

(b, c) Resistance of root elongation to (b) $20 \mu \mathrm{m}$ PCIB or (c) $30 \mathrm{~nm}$ 2,4-D. Root length was measured after 10 days and expressed relative to untreated wildtype. Bars show mean \pm SD for at least 9 (b) or 12 (c) seedlings.

(d) Lateral root stimulation. Data show the mean number ( $\pm S D, n \geq 12$ ) of emerging lateral roots for selected lines transferred when 5 days old to DMSO or 2,4-D and grown for another 5 days. In (c) and (d), data are also shown for transgenic lines with vector only [pB7GWIWG2(II), line F] for comparison. (e) Hypocotyl length. Data show the mean length ( $\pm \mathrm{SD}, n \geq 11$ ) of hypocotyls of untreated, 5-day-old seedlings, grown in the light. 


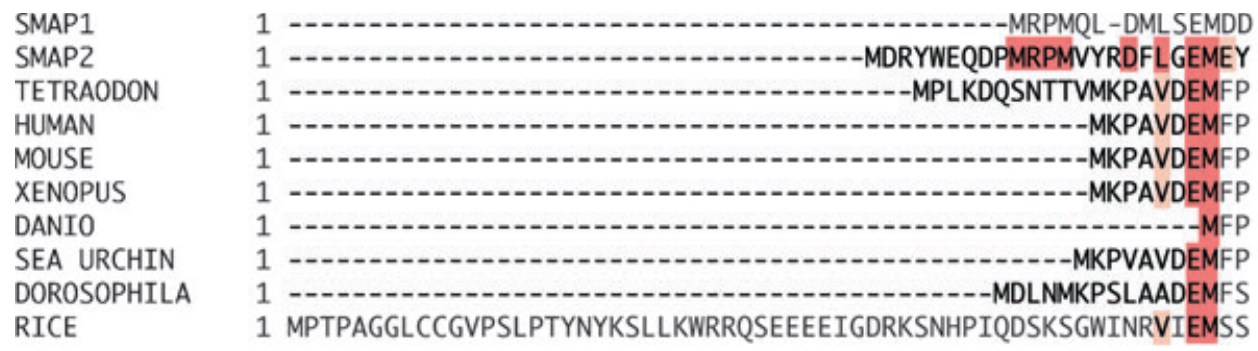

SMAP1
SMAP2
TETRAODON
HUMAN
MOUSE
XENOPUS
DANIO
SEA URCHIN
DOROSOPHILA
RICE

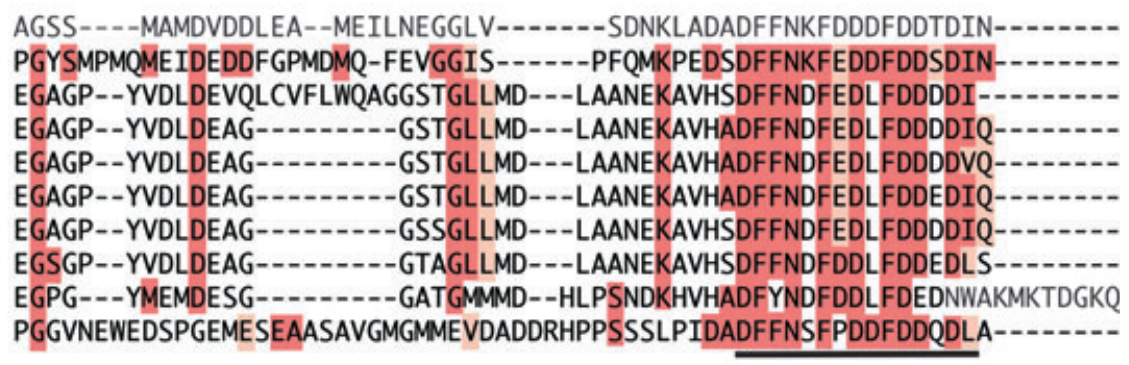

F/D rich region

Figure 10. Alignment of putative SMAP1 homologues.

The $A$. thaliana SMAP1 sequence is shown at the top and identical amino acids are shown in red and similar ones in orange. The sequences were obtained from Genbank: A. thaliana SMAP1, NP_567406; A. thaliana SMAP2, NP_189071; Tetraodon species, CAF94193; Homo sapiens, AAL96264; Mus musculus, BAE31120; Xenopus laevis, NP_001005143; Danio rerio, AAH62283; Strongylocentrotus purpuratus, XP_787254; Drosophila melonogaster, NP_652383; Oryza sativa, XP_483827.

Merck, Darmstadt, Germany) and developed with chloroform:ethylacetate:formic acid (5:4:1). After running TLC, 15 separated $\mathrm{R}_{f}$ zones were excised and counted to measure radioactivity.

\section{Gene mapping}

Mapping was performed by crossing homozygous aar1-1 to Landsberg erecta and identifying individual mutant plants in the $F_{2}$ based on PCIB resistance, and scoring the linkage of SSLP or CAPS markers. The new SSLP/CAPS markers that were developed are listed in Table S1 and deposited in the Arabidopsis Information Resource (http://www.arabidopsis.org/).

\section{Complementation and RNAi experiments}

For complementation analysis, T6G15 BAC DNA was digested by appropriate restriction enzymes and resulting DNA fragments were ligated into a binary vector, either pPZP121 (Hajdukiewicz et al., 1994), pBIN19 (Bevan, 1984) or SLJ755I5 (http://www.jic.bbsrc.ac.uk/ sainsbury-lab/jj/plasmid-list/plasmid.htm). The aar1-1 plants were transformed with the resulting constructs via Agrobacteriummediated transformation (Clough and Bent, 1998).

For RNAi analysis, T6G15 BAC DNA was subjected to PCR with primers as described in Table S3. The amplified fragments were cloned into the pENTR/D-TOPO cloning vector using a pENTR directional TOPO cloning kit (Invitrogen), followed by assembling the fragments into a gateway binary RNAi vector pB7GWIWG2(II) by the LR reaction (Karimi et al., 2002; http://www.psb.ugent.be/gateway/). Wild-type plants were transformed with the resulting constructs via Agrobacterium-mediated transformation.

To estimate the amount of SMAP1 transcript by RT-PCR, we used a Transcriptor First Strand cDNA Synthesis Kit (Roche Diagnostics Corporation, Indianapolis, IN, USA). cDNA was prepared with oligo(dT) primer from $0.5 \mu \mathrm{g}$ of total RNA in a $20 \mu \mathrm{l}$ reaction mixture. The primer sequences used for the PCR step are described in Table S3.

\section{Acknowledgements}

We thank Yoshihiro Hase (Japan Atomic Energy Research Institute) for ion-beam-mutagenized $\mathrm{M}_{2}$ seeds; Jane Murfett and Tom Gulifoyle (University of Missouri, Columbia, MO, USA) for the DR5:GUS line; Ottoline Leyser and Stefan Kepinski (University of York, York, UK) for the HS:AXR3NT-GUS lines; Joe Simorowski and Robert Martienssen (Cold Spring Harbor Laboratory,Cold Spring Harbor, NY, USA) for ET lines; Brent Kaiser (Australian National University, Canberra, Australia) for the amt1;1::T-DNA line; Christiane Genetello (University of Ghent, Belgium) for the pB7GWIWG2(II) vector; Jonathan D. G Jones (The Sainsbury Laboratory, Norwich, UK) for the SLJ755I5 vector; the Arabidopsis Biological Resource Center and Nottingham Arabidopsis Stock Center for providing T-DNA mutants and BAC clones; Alex Bannigan (University of Massachusetts, Amherst, MA, USA) for help with the figures; and Chihiro Suzuki (Japan Atomic Energy Research Institute, Takasaki, Japan) for sequencing. This work was supported in part by postdoctoral fellowships (to A.R and K.K.B) from the Japan Society for Promotion of Science (JSPS), the US National Science Foundation (award number IBN 0316876) to T.I.B., and JSPS Grantin Aid (number 1650042) to Y.O.

\section{Supplementary Material}

The following supplementary material is available for this article online:

Figure S1. Effect of hormones and other compounds on wild-type and aar1-1 root growth.

Figure S2. Germination of wild-type and aar1-1 seeds on auxin and abscisic acid. 
Figure S3. Steps in the positional mapping of aar1.

Table S1 New markers used for mapping

Table S2 T-DNA and enhancer trap (ET) lines tested for PCIB resistance

Table S3 Primers used in RNAi and RT-PCR experiments

This material is available as part of the online article from http:// www.blackwell-synergy.com

\section{References}

Åberg B. (1950) On auxin antagonists and synergists in root growth. Physiol. Plant. 3, 447-461.

Åberg B. (1951) The interaction of some auxin antagonists and 2,4-D in root growth. Physiol. Plant. 4, 627-640.

Abel S., Nguyen M.D. and Theologis A. (1995) The PS-IAA4/5-like family of early auxin-inducible mRNAs in Arabidopsis thaliana. J. Mol. Biol. 251, 533-549.

Bevan M. (1984) Binary Agrobacterium vectors for plant transformation. Nucleic Acids Res. 12, 8711-8721.

Brady S.M., Sarkar S.F., Bonetta D. and McCourt P. (2003) The ABSCISIC ACID INSENSITIVE 3 ( $A B \mid 3)$ gene is modulated by farnesylation and is involved in auxin signaling and lateral root development in Arabidopsis. Plant J. 34, 67-75.

Burström H. (1950) Studies on growth and metabolism of roots. IV. Positive and negative auxin effects on cell elongation. Physiol. Plant. 3, 277-292.

Campanoni P. and Nick P. (2005) Auxin-dependent cell division and cell elongation. 1-Naphthaleneacetic acid and 2,4-dichlorophenoxyacetic acid activate different pathways. Plant Physiol. 137, 939-948.

Chhun T., Taketa S., Ichii M. and Tsurumi S. (2005) Involvement of ARM2 in the uptake of indole-3-butyric acid in rice (Oryza sativa L.) roots. Plant Cell Physiol. 46, 1161-1164.

Clough S.J. and Bent A.F. (1998) Floral dip: a simplified method for Agrobacterium-mediated transformation of Arabidopsis thaliana. Plant J. 16, 735-743.

Delbarre A., Muller P., Imhoff V., Morgat J.L. and Barbier-Brygoo H. (1996) Comparison of mechanisms controlling uptake and accumulation of 2,4-dichlorophenoxy acetic acid, naphthalene-1acetic acid, and indole-3-acetic acid in suspension-cultured tobacco cells. Planta, 198, 532-541.

Dharmasiri N. and Estelle M. (2004) Auxin signaling and regulated protein degradation. Trends Plant Sci. 9, 302-308.

Dharmasiri N., Dharmasiri S. and Estelle M. (2005) The F-box protein TIR1 is an auxin receptor. Nature, 435, 441-445.

Fujita H. and Syono K. (1996) Genetic analysis of the effects of polar auxin transport inhibitors on root growth in Arabidopsis thaliana. Plant Cell Physiol. 37, 1094-1101.

Gray W.M., Kepinski S., Rouse D., Leyser O. and Estelle M. (2001) Auxin regulates $\mathrm{SCF}^{\mathrm{TIR} 1}$-dependent degradation of AUX/IAA proteins. Nature, 414, 271-276.

Hajdukiewicz P., Svab Z. and Maliga P. (1994) The small, versatile pPZP family of Agrobacterium binary vectors for plant transformation. Plant Mol. Biol. 25, 989-994.

Hase Y., Tanaka A., Baba T. and Watanabe H. (2000) FRL1 is required for petal and sepal development in Arabidopsis. Plant J. 24, 21-32.

Imhoff V., Muller P., Guern J. and Delbarre A. (2000) Inhibitors of the carrier-mediated influx of auxin in suspension-cultured tobacco cells. Planta, 210, 580-588.

Jackson R.G., Kowalczyk M., Li Y., Higgins G., Ross J., Sandberg G. and Bowles D.J. (2002) Over-expression of an Arabidopsis gene encoding a glucosyltransferase of indole-3-acetic acid: phenotypic characterisation of transgenic lines. Plant J. 32, 573-583.
Jönsson A. (1961) Chemical structure and growth activity of auxin and antiauxins. In Encyclopedia of Plant Physiology, Vol. 14 (Ruhland, W., ed.). Berlin: Springer, pp. 959-1006.

Kaiser B.N., Rawat S.R., Siddiqi M.Y., Masle J. and Glass A.D.M. (2002) Functional analysis of an Arabidopsis T-DNA "knockout" of the high-affinity $\mathrm{NH}^{+}$transporter AtAMT1;1. Plant Physiol. 130, 1263-1275.

Karimi M., Inze D. and Depicker A. (2002) GATEWAY ${ }^{\top \mathrm{M}}$ vectors for Agrobacterium-mediated plant transformation. Trends Plant Sci. 7, 193-195.

Kawano N., Kawano T. and Lapeyrie F. (2003) Inhibition of the indole-3-acetic acid-induced epinastic curvature in tobacco leaf strips by 2,4-dichlorophenoxyacetic acid. Ann. Bot. 91, 465471.

Kepinski S. and Leyser O. (2005) The Arabidopsis F-box protein TIR1 is an auxin receptor. Nature, $435,446-451$.

Morris D.A. (2000) Transmembrane auxin carrier systems - dynamic regulators of polar auxin transport. Plant Growth Regul. 32, 161172.

Okada K., Ueda J., Komaki M.K., Bell C.J. and Shimura Y. (1991) Requirement of the auxin polar transport system in early stage of Arabidopsis floral bud formation. Plant Cell, 3, 677-684.

Oono Y., Chen Q.G., Overvoorde P.J., Köhler C. and Theologis A. (1998) age mutants of Arabidopsis exhibit altered auxin-regulated gene expression. Plant Cell, 10, 1649-1662.

Oono Y., Ooura C., Rahman A., Aspuria E.T., Hayashi K.-i., Tanaka A. and Uchimiya H. (2003) p-Chlorophenoxyisobutyric acid impairs auxin response in Arabidopsis root. Plant Physiol. 133, 11351147.

Ottenschläger I., Wolff P., Wolverton C., Bhalerao R.P., Sandberg G., Ishikawa H., Evans M. and Palme K. (2003) Gravity-regulated differential auxin transport from columella to lateral root cap cells. Proc. Natl Acad. Sci. USA, 100, 2987-2991.

Poupart J. and Waddell C.S. (2000) The rib1 mutant is resistant to indole-3-butyric acid, an endogenous auxin in Arabidopsis. Plant Physiol. 124, 1739-1751.

Poupart J., Rashotte A.M., Muday G.K. and Waddell C.S. (2005) The rib1 mutant of Arabidopsis has alterations in indole-3-butyric acid transport, hypocotyl elongation, and root architecture. Plant Physiol. 139, 1460-1471.

Pufky J., Qiu Y., Rao M., Hurban P. and Jones A. (2003) The auxininduced transcriptome for etiolated Arabidopsis seedlings using a structure/function approach. Funct. Integr. Genomics 3, 135143.

Rahman A., Ahamed A., Amakawa T., Goto N. and Tsurumi S. (2001) Chromosaponin I specifically interacts with AUX1 protein in regulating the gravitropic response of Arabidopsis roots. Plant Physiol. 125, 990-1000.

Ribnicky D.M., Ilic N., Cohen J.D. and Cooke T.J. (1996) The effects of exogenous auxins on endogenous indole-3-acetic acid metabolism (the implications for carrot somatic embryogenesis). Plant Physiol. 112, 549-558.

Riov J., Cooper R. and Gottlieb H.E. (1979) Metabolism of auxin in pine tissues: naphthaleneacetic acid conjugation. Physiol. Plant. 46, 133-138.

Rubery P. (1995) Auxin transport. In Plant Hormones: Physiology, Biochemistry and Molecular Biology (Davies, P.J., ed.). Dordrecht, The Netherlands: Kluwer Academic Publishers, pp. 341-362.

Staswick P.E., Serban B., Rowe M., Tiryaki I., Maldonado M.T., Maldonado M.C. and Suza W. (2005) Characterization of an Arabidopsis enzyme family that conjugates amino acids to indole-3acetic acid. Plant Cell, 17, 616-627.

Steiger P.A., Reinhardt D. and Kuhlemeier C. (2002) The auxin influx carrier is essential for correct leaf positioning. Plant J. 32, 509-517. 
Sterling T.M. and Hall B.K. (1997) Mechanism of action of natural auxins and the auxinic herbicides. In Herbicide Activity: Toxicology, Biochemistry and Molecular Biology (Roe, R.M., Burton, J.D. and Kuhr, R.J., eds). Amsterdam: IOS Press, pp. 111-141.

Sugaya S. and Sakai S. (1996) Identification of a soluble auxinbinding protein as a glutathione-dependent formaldehyde dehydrogenase. Plant Sci. 114, 1-9.

Sugaya S., Ohmiya A., Kikuchi M. and Hayashi T. (2000) Isolation and characterization of a $60 \mathrm{kDa}$ 2,4-D-binding protein from the shoot apices of peach trees (Prunus persica L.); it is a homologue of protein disulfide isomerase. Plant Cell Physiol. 41, 503-508.

Sundaresan V., Springer P., Volpe T., Haward S., Jones J.D., Dean C., Ma H. and Martienssen R. (1995) Patterns of gene action in plant development revealed by enhancer trap and gene trap transposable elements. Genes Dev. 9, 1797-1810.
Taiz L. and Zeiger E. (2002) Auxin. In Plant Physiology, 3rd edn (Taiz L. and Zeiger E., ed.). Sunderland, MA: Sinauer Associates Inc., pp. 423-460.

Ullah H., Chen J.-G., Young J.C., Im K.-H., Sussman M.R. and Jones A.M. (2001) Modulation of cell proliferation by heterotrimeric G protein in Arabidopsis. Science, 292, 2066-2069.

Ullah H., Chen J.-G., Temple B., Boyes D.C., Alonso J.M., Davis K.R., Ecker J.R. and Jones A.M. (2003) The $\beta$-Subunit of the Arabidopsis $G$ protein negatively regulates auxin-induced cell division and affects multiple developmental processes. Plant Cell, 15, 393-409.

Ulmasov T., Murfett J., Hagen G. and Guilfoyle T.J. (1997) Aux/IAA proteins repress expression of reporter genes containing natural and highly active synthetic auxin response elements. Plant Cell, 9, 1963-1971.

Woodward A.W. and Bartel B. (2005) Auxin: regulation, action, and interaction. Ann. Bot. 95, 707-735. 